\title{
Autologous Peripheral Blood Stem Cells Increase the Telomere Length in Patient: A Case Report of 13 Patients
}

\section{Ciro Gargiulo1*, Van H Pham², Kieu CD Nguyen', Vo LH Trieu', Thao H Duy³, Kenji Abe', Sergey Aityan ${ }^{5}$ and Melvin Shiffman ${ }^{6}$}

${ }^{1}$ Human International Medical Center/Tan Tao University, HCM City, Vietnam

${ }^{2}$ Nam Khoa Bioteck LTD/Tan Tao University, HCM City, Vietnam

${ }^{3}$ Department of Stem Cells, Pham Ngoc Thach University of Medicine, HCM City, Vietnam

${ }^{4}$ Japan National Institute of Infectious Disease, Tokio, Japan

${ }^{5}$ Lincoln University, Oakland CA, USA

${ }^{6}$ Private Consultant, Tustin CA, USA

\begin{abstract}
Telomere dysfunction, which leads to genomic instability, is assumed to play a major role in the development of degenerative diseases as Cancer, Multiple Sclerosis (MS), Amyotrophic Lateral Sclerosis (ALC), Alzheimer's Disease (AD), dementia and diabetes. However, the few epidemiologic studies that assessed the relationship between telomere length in blood cells and autologous peripheral blood stem cells (PB-SCs) have been quite erratic. Cell senescence process, still remains an exciting biological process that is characterized by important structural and morphological changes that involves deviations and alterations in nuclear structure, DNA activity in protein processing and metabolism, and apoptosis resistance.

The associations between telomere length from peripheral blood leucocytes before and after infusion with autologous PB-SCs were examined in 13 case studies that were conducted at our facility. Using value range from 1.5 $\mathrm{Kb}$ to $>20 \mathrm{~Kb}$ as a cut point, patients showed a significant increase of telomere length compared before the infusion of autologous PB-SCs. Meanwhile, there was a substantial improvement in terms of general health such as sleeping, attention, vitality, memory and sexual activity with a significant difference in the quality of life. Overall telomere length from blood was significantly associated with the injection of autologous PB-SCs and as far as 6 months after the injection.
\end{abstract}

Keywords: Amyotrophic lateral sclerosis; Multiple sclerosis; Alzheimer's disease; Stem cells

\section{Introduction}

During the past few years, important results have been achieved in trying to corroborate the essential role of senescence process in human body [1]. Senescence may exhibit a negative impact on organ, tissue and cell regeneration through a release of host bioactive molecules, including Reactive Oxygen Species (ROS) and a wide variety of proinflammatory cytokines, chemokines and growth factors known as the Senescence-Associated Secretory Phenotype (SASP) [1]. Senescence process have been associated with few metabolic degenerative diseases, such as cardiovascular disease, diabetes, atherosclerosis and cancer. Currently, the major challenge in the field is to determine the association between senescent cells and age-related tissue dysfunction, define if this is just a question of correlation or there is cause-effect condition or both [1-3].

Telomeres are specialized DNA-protein arrangements that close the final parts of linear chromosomes. Functional telomeres need appropriate extension of telomeric DNA repeats to keep chromosomal stability. Any dysfunction on this part of DNA lead to chromosome end-to-end fusion, chromosomal changes and instabilities that may eventually lead to degenerative disease such as cancer [2]. Vertebrate telomeres are composed of variable numbers of a tandem repeat sequence of TTAGGG, bound to three shelterin subunits, TRF1, TRF2, and POT1 [4]. During each cell division telomeres reduce, a process supposed to be enhanced by oxidative stress and inflammation, telomerase preserve and maintains telomere length and stability. Very short or dysfunctional telomeres trigger replicative senescence, a process that may be activated by a single critically short telomere in a cell $[5,6]$. According to some scientist, the telomere length can be used as early predictive indicator in serious life threatening diseases, for instance very short telomeres are seen in pre-malignant lesions, atypical hyperplasia and several form of carcinoma in humans [7-11]. However, whether overall telomere length from blood cells is associated with cancer risk remains unclear; recently, two of our recent examined patient showed an abnormal extent telomere which confirmed in both cases a specific tissue lesion a Barrett's syndrome and a liver cholestasis (data not shown). As similarly described by Finley et al. in their study, an increase in telomerase expression would be compatible with an increase in histologic grade which allows the growth of telomere length [12]. In this paper we conducted a 13 independent case-control study to investigate further whether the overall telomere length from blood sample may respond to a treatment of autologous PB-SCs.

Based on our previous edited study human PB revealed the presence of different sub-groups of pluripotent and multipotent stem cells. The use of reverse transcription polymerase chain reaction (RT PCR) and fowcytometry analysis confirmed the expression of multipotent markers of both adherent and non-adherent mononucleated cells such as Oct4, Sox2, OCN, Nestin, Nanog, DMP and CD44, CD73, CD90, CD133, CD 34, CD45, CD14, Nestin, SSEA3 and Tra1. The study also quantified

${ }^{*}$ Corresponding author: Ciro Gargiulo, Human International Medical Center/Tan Tao University, HCM City, Vietnam, Tel: +8939778130, +89-903693884; Fax: +89 38256724; E-mail: drciroisacco@gmail.com

Received July 18, 2016; Accepted August 06, 2016; Published August 12, 2016

Citation: Gargiulo C, Pham VH, Nguyen KCD, Trieu VLH, Duy TH, et al. (2016) Autologous Peripheral Blood Stem Cells Increase the Telomere Length in Patient: A Case Report of 13 Patients. J Stem Cell Res Ther 6: 352. doi: 10.4172/2157 7633.1000352

Copyright: (c) 2016 Gargiulo C, et al. This is an open-access article distributed under the terms of the Creative Commons Attribution License, which permits unrestricted use, distribution, and reproduction in any medium, provided the original author and source are credited. 
the presence of 14 hormones in extracellular matrix components into the stem cell culture supernatants together with presence of high level pro/anti-inflammatory cytokines such as TNFa, IL-6, IFNy and IL-2 [13]. The autologous PB-SCs were used successfully in two infectious cases HIV and Toxo plasma gondii, cases that were published as case reports. The results showed the potential of PB-SCs in enhancing host immunity against virus, bacteria and parasites $[14,15]$.

\section{Materials and Methods}

\section{Patients}

We enrolled all participants during 2015-2016. Eligible participants were men/women with diverse condition having chosen stem cell therapy rather than conventional treatment (for reasons unrelated to the study), so it was possible to assess the association between changes in lifestyle and changes in telomere length without potentially confounding treatments. There were not specific inclusion criteria the protocol for this study was approved by the TTU institutional review board. All participants provided written informed consent.

\section{Interventions}

Participants underwent some basic medical check and screen. After the first 3 months meetings were not compulsory, but patients could continue to meet on their own for two $4 \mathrm{~h}$ meetings per month for the duration of the study. A physician or nurse was on site during meetings and patients could request that other clinical staff attend or be available by telephone at these times, as needed. The protocol previews the withdrawal of $35 \mathrm{ml}$ of peripheral blood from a cubital vein 10 times. After the basic isolation procedure was completed in the laboratory, mononuclear cells were cultured in T25 flask for a period of 7-8 days. The harvesting procedure was accomplished by enzymatic activity, and once completed cells were washed by PBS twice and collected with the patient's own serum obtained by centrifugation by $9 \mathrm{ml}$ of fresh blood. The collected PB-SCs were injected either systemically or subcutaneously.

Peripheral blood mononuclear cells $35 \mathrm{~mL}$ blood was drawn from participants into heparin tubes at baseline. The samples were anonymized so that laboratory technicians were unaware of treatment group and collection time. PB-SCs were isolated within $1 \mathrm{~h}$ with Ficoll gradient (Ficoll-Paque PLUS, GE Healthcare, Pittsburgh, PA, USA) with ratio 1:2 (1 portion Ficoll, 2 portions blood). Viable PB-SCs were counted with the Trypan blue exclusion method (0.4\% Trypan blue stain, Invitrogen, Grand Island, NY, USA) of $10^{7} / \mathrm{mL}$. Primary PB-SCs were cultured in 25-T flasks (Nunc-thermo scientific USA) with $5 \mathrm{ml}$ SFM medium (Gibco Technologies USA) and incubated at $37^{\circ} \mathrm{C}-05 \%$ $\mathrm{CO}_{2}$ for 48 hours. PB-SCs (attached ones) were harvested by using 2 $\mathrm{ml}$ trypsin-EDTA and collected in $2 \mathrm{~mL}$ patient's serum. Viable cells were counted using the Trypan blue exclusion method to obtain $10^{6}$ cells $/ \mathrm{ml}$. After centrifugation at $3500 \mathrm{rpm}(5024 \mathrm{~g})$ in a refrigerated microcentrifuge (Silfradent, Bologna, Italy) at $4^{\circ} \mathrm{C}$ for $15 \mathrm{~min}$, cells/ pellets at the bottom was aspirated off.

\section{Telomere length measurement}

Real-time telomere quantitative PCR (qPCR) was used for the telomere length measurements. The methods is well established and has been shown to be reliable process to measure the telomere length in previous scientific studies and in basic research. Lymphocytes were collected from fresh blood by venipuncture into vacutainer blood tubes (Silfradent heparine). The blood was diluted blood 1:1 with HBSS and gently invert to mix Overlay diluted blood onto $1 / 3$ volume of
Ficoll-Paque and centrifuged $400 \mathrm{~g}$ for $30 \mathrm{~min}$ at $20^{\circ} \mathrm{C}$. Lymphocyte layer were moved to a fresh tube using a Pasteur pipette and diluted with $3 \mathrm{X}$ volume HBSS at room temperature the whole was then centrifuged at $180 \mathrm{~g}$ for 10 minutes. Once supernatant was discarded the cell pellet were re-suspended with in HBSS. Cell count and viability test was performed by using haemocytometer and trypan blue. The real-time qPCR method described by O'Callaghan and Fenech was used based on the Cawthon procedure for relative measurement of Telomere Length (TL) with a modification that considered the use of an oligomer standard to quantify a TL. Power SYBR I mastermix (Applied Biosystems, \#4367396). Contains AmpliTaq Gold DNA polymerase, dNTPs, SYBR I Green Dye, opitimised buffers and passive reference dye (ROX). For this study, the $\beta$-globin gene (hgb) was used as the single copy reference. Real time kinetic quantitative PCR determines the fractional cycle $(\mathrm{Ct})$ number at which the well's accumulating fluorescence crosses a set threshold of 40 that is several standard deviations above baseline fluorescence. A standard curve is established by dilution of known quantities of a synthesized 84 mer oligonucleotide containing only TTAGGG repeats. The number of repeats in each standard is calculated using standard techniques, the oligomer standard is $84 \mathrm{bp}$ in length (TTAGGG repeated 14 times), with a molecular weight (MW) of 26667.2 , the weight of telomere standard is: $2.6667 \times 104 / 6.02 \times 1023=0.44 \times 10^{-19} \mathrm{~g}$. The highest concentration standard (TEL STD A) has $60 \mathrm{pg}$ of telomere oligomer $\left(60 \times 10^{-12} \mathrm{~g}\right)$ per reaction, thus there are $60 \times 10^{-12} / 0.44 \times 10^{-19}=1.36 \times 10^{9}$ molecules of oligomer in TEL STD A. The quantity of telomere sequence in TEL STD A is calculated based on the formula: $1.36 \times 10^{9} \times 84$ (oligomer length) $=1.18 \times 10^{8} \mathrm{~kb}$ of telomere sequence in TEL STD A. A standard curve has been obtained by a calculation based on aTL qPCR assay on serial dilutions of TEL STD A $\left(10^{-1}\left[1.18 \times 10^{8}\right]\right.$ through to $10^{-6}\left[1.18 \times 10^{3}\right]$ dilution). In order to keep a constant $20 \mathrm{ng}$ of total DNA per reaction tube plasmid DNA (pBR322) was supplemented to each standard. The information of telomeric sequence per sample in $\mathrm{kb}$ was measured by using the standard curve.

\section{Results and data analysis}

13 out of 13 patients from the intervention group revealed sufficient baseline samples of PB-SCs to assess relative telomere length before and after the procedure. However, 1 patient telomere length reduced after the treatment and 1 patient over growth. Baseline characteristics of patients were similar, although in view of the size of the groups there was not sufficient power to detect small differences between them (Table 1).

The null hypothesis was formulated that two samples for telomere function cell growth rate before and after the PB-SCs treatment belong to the same population. It means that there is no difference between the data sets presented in these two samples, before and after PB-SCs treatment, i.e.

$$
H_{0}: \mu\left(X_{\text {After }}-X_{\text {Before }}\right)=0
$$

where $\mathrm{X}$ is the variable measured in a sample.

The similar null hypothesis Eq.(1) was formulated for the data samples representing the telomere length in chromosome before and after PB-SCs treatment.

Student's t-test was conducted on two paired samples of telomere function cell growth before and after the PB-SCs treatment and on another two paired samples of telomere length in chromosome data before and after the PB-SCs treatment.

The $\mathrm{t}$-test identified that with standard error $\alpha=5 \%$ (significance 
Citation: Gargiulo C, Pham VH, Nguyen KCD, Trieu VLH, Duy TH, et al. (2016) Autologous Peripheral Blood Stem Cells Increase the Telomere Length in Patient: A Case Report of 13 Patients. J Stem Cell Res Ther 6: 352. doi: 10.4172/2157-7633.1000352

Page 3 of 6

\begin{tabular}{|c|c|c|c|c|c|c|c|c|c|c|}
\hline \multicolumn{3}{|c|}{ Study Group } & \multicolumn{4}{|c|}{ Telomere function cell Growth (Kb) } & \multicolumn{4}{|c|}{ Telomere length in Chromosome (Kb) } \\
\hline \# & Gender & Age & Before & After & Change & $\%$ Change & Before & After & Change & $\%$ Change \\
\hline 1 & Male & 84 & 120.7 & 210 & 89.3 & $74 \%$ & 5.2 & 9.1 & 3.9 & $75 \%$ \\
\hline 2 & Male & 74 & 34.6 & 241 & 206.4 & $597 \%$ & 1.5 & 10.4 & 8.9 & $593 \%$ \\
\hline 3 & Male & 58 & 158.3 & 256.6 & 98.3 & $62 \%$ & 6.88 & 11.2 & 4.32 & $63 \%$ \\
\hline 4 & Female & 71 & 78.8 & 361 & 282.2 & $358 \%$ & 3.4 & 15.7 & 12.3 & $362 \%$ \\
\hline 5 & Female & 72 & 111 & 208 & 97 & $87 \%$ & 4.8 & 9 & 4.2 & $88 \%$ \\
\hline 6 & Female & 61 & 153.7 & 183 & 29.3 & $19 \%$ & 6.7 & 12.3 & 5.6 & $84 \%$ \\
\hline 7 & Female & 64 & 287.5 & 376.8 & 89.3 & $31 \%$ & 12.5 & 16.3 & 3.8 & $30 \%$ \\
\hline 8 & Female & 64 & 345.5 & 390 & 44.5 & $13 \%$ & 15 & 16.9 & 1.9 & $13 \%$ \\
\hline 9 & Male & 56 & 349 & 786.3 & 437.3 & $125 \%$ & 15.1 & 34.1 & 19 & $126 \%$ \\
\hline 10 & Male & 54 & 679.2 & 341.3 & -337.9 & $-50 \%$ & 29.5 & 14.8 & -14.7 & $-50 \%$ \\
\hline 11 & Male & 55 & 138 & 504 & 366 & $265 \%$ & 6 & 21 & 15 & $250 \%$ \\
\hline 12 & Female & 56 & 122.3 & 261.6 & 139.3 & $114 \%$ & 5.3 & 11.4 & 6.1 & $115 \%$ \\
\hline 13 & Female & 54 & 324.3 & 453.6 & 129.3 & $40 \%$ & 14.1 & 19.7 & 5.6 & $40 \%$ \\
\hline \multicolumn{3}{|c|}{ Mean } & 223.3 & 351.8 & 128.5 & $133.5 \%$ & 9.691 & 15.53 & 5.840 & $137.5 \%$ \\
\hline \multicolumn{3}{|c|}{ Standard Deviation } & 173.0 & 164.2 & 187.3 & $176.5 \%$ & 7.515 & 6.781 & 7.951 & $172.7 \%$ \\
\hline
\end{tabular}

Table 1: Telomere function cell growth and length in chromosome before and after treatment with the stem cells.
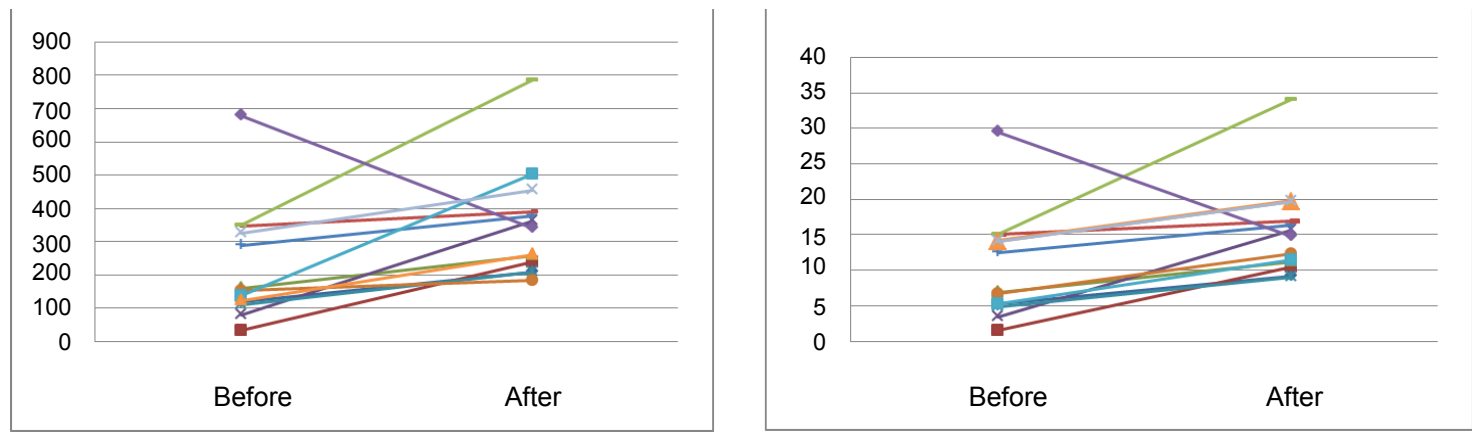

Figure 1: Change of telomere function cell growth (a) and telomere length in chromosome (b) before and after the PB-SCs treatment.

level 95\%) both null hypothesis, for the telomere function cell growth and the telomere length in chromosome samples failed. Thus both null hypotheses were rejected. It means that the samples before and after PB-SCs treatment are statistically different. The telomere function cell growth rate and the telomere length in chromosome before and after the PB-SCs treatment are significantly different.

We cannot make any conclusion about the causes of those changes because there were no samples collected on control groups. However, we can conclude that the registered changes in telomere function cell growth rate and the telomere length in chromosome before and after the PB-SCs treatment are statistically significant.

Figure 1 shows the change in the telomere function call growth and the change in the telomere length in chromosome before and after the PB-SCs treatment for each patient in the group. As is evident from the figure, both, telomere function cell growth and the telomere in chromosome has increased after the treatment for all patients except one.

Table 1 and Figure 2 show that the telomere function cell growth after the treatment is higher when the telomere function cell growth was higher before the treatment.

The diagonal blue line in Figure 2 indicates that all, except just one, readings after the treatment are higher than the related reading before the treatment. The trendline is also shown in Figure 2 together with the R-squared value. The correlation coefficient between the telomere function cell growth before and after the PB-SCs treatment is

$$
\rho_{\mathrm{BA}}^{\text {Growth }}=0.38
$$

The trendline slope in the figure and the correlation coefficient are related by the ratio of the standard deviations in the samples before and after.

Table 1 and Figure 3 show that the telomere length in chromosome after the treatment is higher when the telomere length in chromosome was higher before the treatment.

The diagonal blue line in Figure 3 indicates that all, except just one, readings after the treatment are higher than the related reading before the treatment. The trendline is also shown in Figure 2 together with the R-squared value. The correlation coefficient between the telomere length in chromosome before and after the PB-SCs treatment

$$
\rho_{\mathrm{BA}}^{\text {Length }}=0.38
$$

Table 1 and Figure 2 show that the percentage change of the telomere function cell growth before and after the treatment was higher with the higher percentage change of the telomere function cell growth before the PB-SCs treatment (Figure 4). 


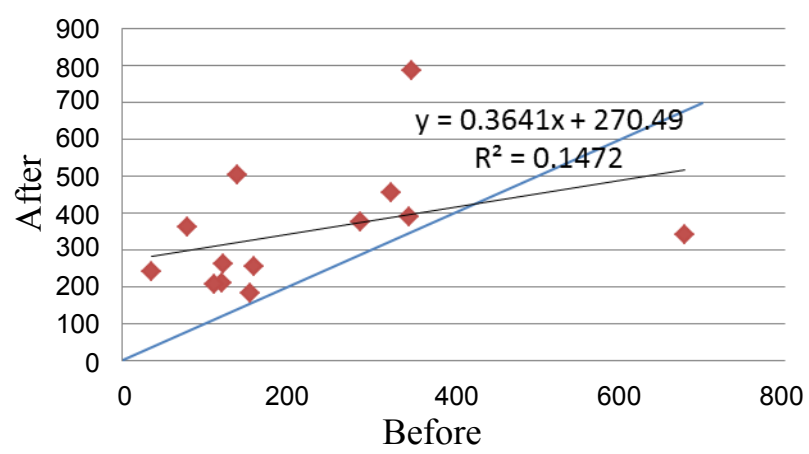

Figure 2: Telomere function cell growth before and after the PB-SCs treatment.

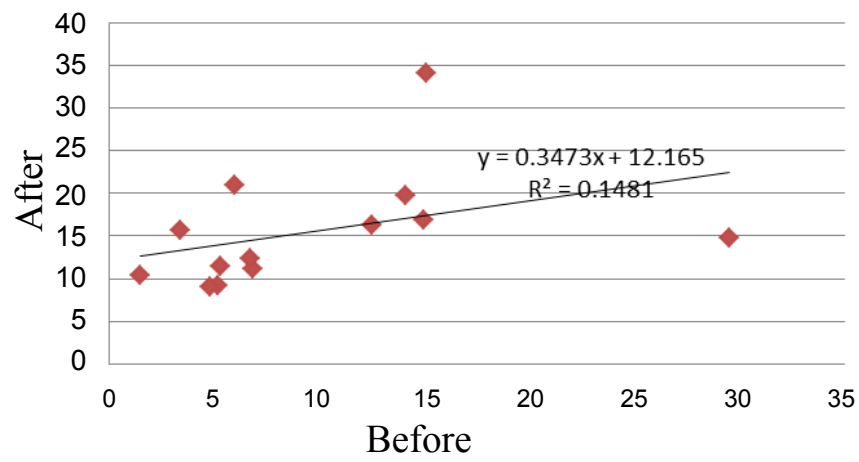

Figure 3: Telomere length in chromosome before and after the PB-SCs treatment.

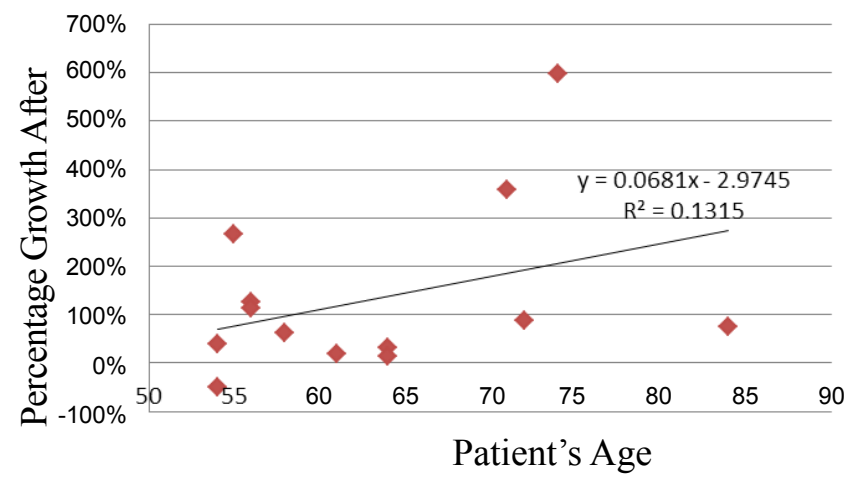

Figure 4: Telomere percentage change in function cell growth before and after the PB-SCs treatment by patient age.

The correlation coefficient between the telomere function cell growth before and after the PB-SCs treatment

$$
\rho_{\mathrm{A} \_ \text {Age }}^{\text {Growth }}=0.36
$$

Table 1 and Figure 5 show that the percentage change of the telomere length in chromosome before and after the treatment was higher with the higher percentage change of the telomere length before the PB-SCs treatment.
The correlation coefficient between the telomere length in chromosome before and after the PB-SCs treatment

$$
\rho_{\mathrm{A} \text { Age }}^{\text {Length }}=0.37
$$

All correlation in Eqs.(1)-(4) are medium low positive.

\section{Discussion}

Our findings clearly point out that the difference in telomere length and replicative response after injection with autologous PBSCs of subjects in this group. Shortening of telomeres is the cause of replicative senescence and may be a cause of cellular aging in vivo [15]. Results from human samples have demonstrated that in some tissues cells go through a telomere shortening concomitant to aging process $[16,17]$. Noticeably, it has been confirmed that telomere shortening in aging individuals is something that takes place in human peripheral blood leukocytes, in Peripheral Blood Mesenchymal Stem Cells (PBMCs) and in T cells [18-20]. Whether telomere is directly responsible to the insurgence of a disease or it is just a consequence of a disease, this is still a matter of debate and a conclusion are quite controversial.

Some data tend to associate the shortening telomere to a natural process where immunity dropping as consequence of aging process. Some others as Blackburn, asserted that telomere length "per se" has nothing to do with any mitotic process whilst telomerase is crucial in maintaining cellular generative ability [21-23]. While other scientists, as Greider, are fully resolute about the inconsistency of evidence which endorse any uniformity between in vitro and in vivo cells behavior. Something like, there is nothing that allow us to clinch together changes that may undergo in culture environment with those take place in human molecular micro-environment [24].

We can now report that in a group of patients, 12 out of 13 treated with autologous PB-SCs revealed an increase in telomere length of peripheral blood white cells. The relationship between telomere length and replicative capacity before and after autologous PB-SCs stimulation is significantly different between before and after. Our findings tend demonstrate that elongation of telomeres might be related with a higher replicative capacity after stimulation with PB-SCs adults independent from age. We can only speculate that this phenomenon may have been due to activation of telomerase through series of signaling pathways triggered by stem cells itself.

The mechanism of PB-SCs would probably follow the same pathway as induced pluripotent stem cells (iPS) and ESCs described by Shimamoto et al. The assumption is based on the regular expression

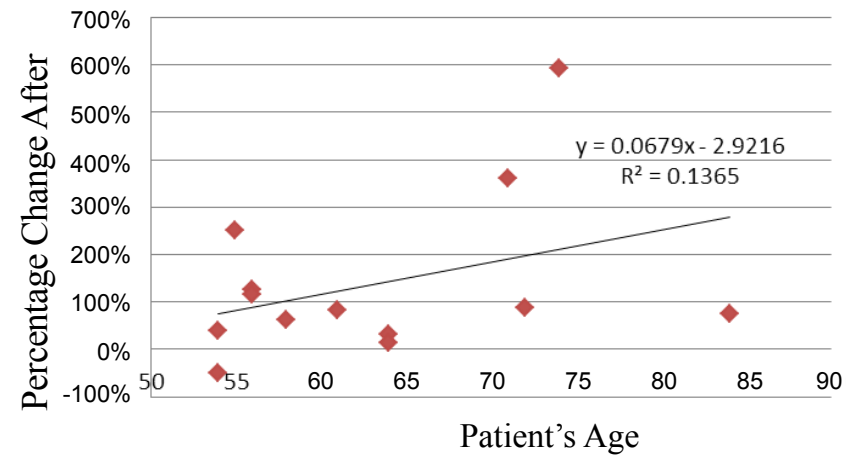

Figure 5: Telomere percentage change of the length in chromosome before and after the PB-SCs treatment by patient age. 
of important pluripotency and multipotency genes by human PBSCs such as Oct4, Sox2, Nanog, OCN, Nestin as well as an osteogenic marker as the dental matrix protein (DMP) $[13,25,26]$.

Pluripotent and multipotent stem cells use the Wnt/ $\beta$-catenin signaling pathway with KLF4 and/or TCF4 and OCT3/4 and NANOG respectively in the activation of telomerase reverse transcriptase subunit (hTERT in humans) and the Telomerase RNA Component (TERC) $[25,26]$. In PB-SCs the telomerase activation induce telomere elongation Telomere elongation accompanied by telomerase activation may lead to the lengthening of telomeres in way to those of ESCs, an event that is probably due to the presence of small pool of ESCs and progenitor MSCs within the totality of PB-SCs. Thus, similarly with iPS and ESCs, PB-SCs may express "epigenetic alterations to ESC-like states with reduced histone codes associated with heterochromatin, and enhanced transcription at the telomere loci" [25]. However, stronger point of PB-SCs vs iPS, it would be the lower chance to encounter telomerase-deficient cells as PB-SCs naturally include pool of cells with multipotency and pluripotency features [13].

We are not aware that the mechanism of telomere elongation as a consequence of replicative stimulation has yet been studied. However, it may be a promising line of research. It is clear that in cells from older subjects this yet unknown mechanism is impaired. Autologous PB-SCs transplantation can be designated as one of the promising therapeutic strategies for treating intractable diseases, including DM2, arthritis, arthrosis, MS, ALS or Alzheimer's. Clinical application of PB-SCs requires safe and stable growth ability and differentiation potential into various cell tissue types that could regenerate the damaged area.

In addition to the safety of PB-SCs, evaluation of whole-genome sequencing and epigenomic analysis would be needed before their clinical application because patient cells may show some chromosomal aberrations including translocations, inversions, and deletions. To examine the association between relative telomere length in blood, we performed a 13 case analysis with infusion of autologous PB-SCs results were compared before and after the treatment, participants completed a baseline questionnaire and home visit. Two out 13 patients revealed either a lowering of telomere or an over increase of telomere. The inconsistency may be due to a number of reasons. Telomere length in peripheral white blood cells may possibly be affected by the presence of malicious condition. As some author stated in case-control studies the link amid short telomere and disease could be a consequence of reverse causation bias [27]. Especially if one considers that many factors such as drugs and chemicals or radio-therapy may cause DNA damage and thus telomere length [28]. Supposedly, long and short telomeres both may be associated with malignancies threats, phenomenon related to cell's microenvironment and somatic mutations. Long telomeres may be associated to insurgence of malignant cells due to the additional rounds of cell division and the accumulation of somatic mutation that may inhibit the natural senescence and apoptosis process evolving into tumor-genesis [29,30].

Conversely, those cells express short telomeres in which apoptosis mechanism is already impaired are predisposed to chromosomal instability due to end-to-end chromosome fusions, condition that may also lead to carcinogenesis $[29,30]$. In the present study we show that the individual blood cell telomere can experience shortening as well as elongation during a rather short period of time. In concordance with previously published data of longer time spans [27-30], there was a negative correlation between baseline RTL and RTL changes over time. As compared to our previously published data from the 10 year study [27], the monthly RTL changes were greater in the 6 month study. In individual cases remarkable TL changes could be observed, best exemplified in the present study by one of the blood donors who showed a loss of $\sim 3.9 \mathrm{kbp}$ in the mean telomere length distribution over a 6 months period and a loss of $9.7 \mathrm{~kb}$ in the upper limit of telomere length. Taken together the data show that blood cell TL in individual cases can be a highly dynamic feature exhibiting considerable length changes over comparatively short periods of time.

The shortening process of telomeres should be probably considered one of the main events of the aging process; each time a cell divides, chromosomes undergo a DNA replication where small portion of DNA are sheared off at the end of the chromosomes. Stem cells in general are needed to repair, regenerate and rebuild. This fact plays a key role in regulating telomeres $[31,32]$. Cells are sensitive to stress and might be irreparably damaged even at a young age. We may regard telomere length measurements as snapshots taken at a certain point in life, a sort of instant photogram that cannot really distinguish between inherited traits and the damages of environmental stressors which may have caused cells to reveal both long and short telomeres. Epel revealed few stressor factors such as stress hormones, oxidative stress and inflammatory stress that may cause stress on a molecular level, creating damage to protein structures and mechanisms of a cell and activating a premature apoptosis mechanism [23,33].

Epigenetic studies have revealed that the stability of telomere in mammalian cells is mainly based on the close relation between a few proteins and their partners. Normal levels of $\mathrm{H} 3 \mathrm{~K} 9 \mathrm{me} 2 / 3$, knockdown of histone H3K9 methyltransferases G9a and SUV39H1, interfere with telomere functionality in cancer cells [34]. Thus as SUV39H1 sets the activity of DNA methyltransferase through HP1 $\beta$ [35], and G9 and its linked protein GLP are also involved in the maintenance of genomic imprinting in the mammalian ES cells [36], DNA methylation might also facilitate the maintenance of telomere length in mammals.

Consequently, the relationship between the length of telomere and aging is a multi-factorial business and requires a thorough understanding of a more complex scenario. Regenerative capacity adopted by the body's constant use of stem cells is strictly interdependent with endogenous and environmental exposures and other sources of oxidative stress that eventually induce internal epigenetic changes. This is a scenario that characterizes an important pathway through which environmental factors influence disease-risk, both within individuals and across generations.

\section{Conclusion}

In this introductory study we revealed that in 12 out of 13 patients TL of peripheral blood white cells responded positively to autologous PB-SCs. However, many questions yet remain to be answered. In the forthcoming research, we need to explore the relationship between stem cells, epigenetic factors, and TL This paper is just a step in a wider study that is going on now at our research facility.

Bias is often present in a research publication and its influence should be always taken into account [37]. In our opinion, the "confounding bias" is the major concern in this study. In this specific case, a confounding bias may occur as it includes observed associations between two events PB-SCs and TL (confounded by internal and external variables) and the association between life style and health status (confounded by age and income). Therefore, to control the confounding bias, a true randomization and a pre-study design have been conducted to match patients by age and gender and threat factors of life-style. 
Citation: Gargiulo C, Pham VH, Nguyen KCD, Trieu VLH, Duy TH, et al. (2016) Autologous Peripheral Blood Stem Cells Increase the Telomere Length in Patient: A Case Report of 13 Patients. J Stem Cell Res Ther 6: 352. doi: 10.4172/2157-7633.1000352

Page 6 of 6

As we would like to understand how much TL is really indicative of each individual's condition, we are investigating whether there is a permeability that may lead to more comprehensive data, and how strong evidence we have to declare that TL may or may not be a predictor of each individual's health "destiny".

Nonetheless, although the exact pathway of events from perception of rejuvenation in somatic cell longevity is unclear, the results reported here may suggest the possibility of opening a debate on the future clinical use of PB-SCs in the field of regenerative medicine.

\section{Acknowledgment}

The authors would like to express their sincere appreciation to Mrs. Libby Zinman-Schwartz for her help in the preparation of this paper.

\section{Conflict of Interest Declaration}

We certify that no funding has been received for the conduct of this study and/ or preparation of this manuscript; the author reveals no conflict of interest for this manuscript.

\section{References}

1. Correia-Melo C, Hewitt G, Passos JF (2014) Telomeres, oxidative stress and inflammatory factors: partners in cellular senescence? Longev Healthspan 3: 1. [PubMed]

2. Gray JW, Collins C (2000) Genome changes and gene expression in human solid tumors. Carcinogenesis 21: 443-452. [PubMed]

3. Buxton J, Suderman M, Pappas JJ, Borghol N, McArdle W, et al. (2014) Human leukocyte telomere length is associated with DNA methylation levels in multiple subtelomeric and imprinted loci. Sci Rep 4: 4954. [PubMed]

4. de Lange $T$ (2005) Shelterin: the protein complex that shapes and safeguards human telomeres. Genes Dev 19: 2100-2110. [PubMed]

5. von Zglinicki T (2002) Oxidative stress shortens telomeres. Trends Biochem Sci 27: 339-344. [PubMed]

6. Hemann MT, Strong MA, Hao LY, Greider CW (2001) The shortest telomere, not average telomere length, is critical for cell viability and chromosome stability. Cell 107: 67-77. [PubMed]

7. Kurz DJ, Decary S, Hong Y, Trivier E, Akhmedov A, et al. (2004) Chronic oxidative stress compromises telomere integrity and accelerates the onset of senescence in human endothelial cells. J Cell Sci 117: 2417-2426. [PubMed]

8. O'Sullivan JN, Bronner MP, Brentnall TA, Finley JC, Shen WT, et al. (2002) Chromosomal instability in ulcerative colitis is related to telomere shortening. Nat Genet 32: 280-284. [PubMed]

9. McGrath M, Wong JY, Michaud D, Hunter DJ, De VI (2007) Telomere length, cigarette smoking, and bladder cancer risk in men and women. Cancer Epidemiology Biomarkers Prevention 16: 815-819. [PubMed]

10. Wu X, Amos Cl, Zhu Y, Zhao H, Grossman BH, et al. (2003) Telomere dysfunction: a potential cancer predisposition factor. J Natl Cancer Inst 95: 1211-1218. [PubMed]

11. Broberg K, Bjork J, Paulsson K, Hoglund M, Albin M (2005) Constitutional short telomeres are strong genetic susceptibility markers for bladder cancer. Carcinogenesis 26: 1236-1271. [PubMed]

12. Finley JC, Reid BJ, Odze RD, Sanchez CA, Galipeau P, et al. (2006) Chromosomal instability in Barrett's esophagus is related to telomere shortening. Cancer Epidemiol Biomarkers Prev 15: 1451-1457. [PubMed]

13. Cawthon RM, Smith KR, O'Brien E, Sivatchenko A, Kerber RA (2003) Association between telomere length in blood and mortality in people aged 60 years or older. Lancet 361: 393-395. [PubMed]

14. Cawthon RM (2002) Telomere measurement by quantitative PCR. Nucleic Acids Res 30: e47. [PubMed]

15. Simon NM, Smoller JW, McNamara KL, Maser RS, Zalta AK, et al. (2006) Telomere shortening and mood disorders: preliminary support for a chronic stress model of accelerated aging. Biol Psychiatry 60: 432-435. [PubMed]
16. Flores I, Cayuela ML, Blasco MA (2005) Effects of telomerase and telomere length on epidermal stem cell behavior. Science 309: 1253-1256. [PubMed]

17. Armanios M, Alder JK, Parry EM, Karim B, Strong MA, et al. (2009) Short telomeres are sufficient to cause the degenerative defects associated with aging. Am J Hum Genet 85: 823-832. [PubMed]

18. Slagboom PE, Droog S, Boomsma DI (1994) Genetic determination of telomere size in humans: a twin study of three age groups. Am J Hum Genet 55: 876882. [PubMed]

19. Iwama H, Ohyashiki K, Ohyashiki JH, Hayashi S, Yahata N, et al. (1998) Telomeric length and telomerase activity vary with age in peripheral blood cells obtained from normal individuals. Hum Gent 102: 397-402. [PubMed]

20. Rufer N, Brummendorf TH, Kolvraa S, Bischoff C, Christensen K, et al. (1999) Telomere fluorescence measurements in granulocytes and $T$ lymphocyte subsets point to a high turnover of hematopoietic stem cells and memory $T$ cells in early childhood. J Exp Med 190: 157-167. [PubMed]

21. Murillo-Ortiz B, Albarrán-Tamayo F, López-Briones S, Martínez-Garza S Benítez-Bribiesca L, et al. (2013) Increased telomere length and proliferative potential in peripheral blood mononuclear cells of adults of different ages stimulated with concanavalin A. BMC Geriatr 13: 99. [PubMed]

22. Yang L, Suwa T, Wright WE, Shay JW, Hornsby PJ (2001) Telomere shortening and decline in replicative potential as a function of donor age in human adrenocortical cells. Mech Ageing Dev 122: 1685-1694. [PubMed]

23. Blackburn EH (2000) Telomere states and cell fates. Nature 408: 53-56. [PubMed]

24. Greider CW (2000) Cellular responses to telomere shortening: cellular senescence as a tumor suppressor mechanism. Harvey Lect 96: 33-50. [PubMed]

25. Shimamoto A, Yokote K, Tahara H (2015) Werner Syndrome-specific induced pluripotent stem cells: recovery of telomere function by reprogramming. Front Genet 6: 10. [PubMed]

26. Suzuki S, Namiki J, Shibata S, Mastuzaki Y, Okano H (2010) The neural stem progenitor cell marker nestin is expressed in proliferative endothelial cells, but not in mature vasculature. J Histochem Cytochem 58: 721-730. [PubMed]

27. Hoffmeyer K, Raggioli A, Rudloff S, Anton R, Hierholzer A, et al. (2012) Wnt//2 catenin signaling regulates telomerase in stem cells and cancer cells. Science 336: 1549-1554. [PubMed]

28. Mirabello L, Yu K, Kraft P, De Vivo I, Hunter DJ, et al. (2010) The association of telomere length and genetic variation in telomere biology genes. Hum Mutat 31: 1050-1058. [PubMed]

29. Schröder CP, Wisman GB, de Jong S, van der Graaf WT, Ruiters MH, et al. (2001) Telomere length in breast cancer patients before and after chemotherapy with or without stem cell transplantation. Br J Cancer 84: 1348-1353. [PubMed]

30. Sharma GG, Gupta A, Wang H, Scherthan H, Dhar S, et al. (2003) hTERT associates with human telomeres and enhances genomic stability and DNA repair. Oncogene 22: 131-146. [PubMed]

31. Wright WE, Shay JW (2005) Nature and Genetics 37: 116-118.

32. Rehman J (2014) Aging: too much telomere can be as bad as too little Scientific American.

33. Epel ES, Blackburn EH, Lin J, Dhabhar FS, Adler NE, et al. (2004) Accelerated telomere shortening in response to life stress. Proc Natl Acad Sci U S A 101 17312-17315. [PubMed]

34. Kondo Y, Shen L, Ahmed S, Boumber Y, Sekido Y, et al. (2008) Downregulation of Histone H3 Lysine 9 Methyltransferase G9a Induces Centrosome Disruption and Chromosome Instability in Cancer Cells. PLoS ONE 3: e2037. [PubMed]

35. Fucks F, Hurd PJ, Wolf D, Kouzarides T (2003) The methyl-CpG-binding protein MeCP2 links DNA methylation to histone methylation. J Biol Chem 278: 4035-4040. [PubMed]

36. Zhang T, Termanis A, Özkan B, Bao XX, Rappsilber J, et al. (2016) G9a/GLP Complex Maintains Imprinted DNA Methylation in Embryonic Stem Cells. Cell Report 15: 77-85.

37. Pannucci CJ, Wilkins EG (2011) Identifying and Avoiding Bias in Research Plast Reconstr Surg 126: 619-625. [PubMed] 